\title{
Visualization of Combustion Phases of Biomass Particles: Effects of Fuel Properties
}

\author{
Yongsheng Jia, Zhicong Li, Yingie Wang, Xun Wang, Chun Lou, * Bo Xiao,* and Mooktzeng Lim \\ Cite This: ACS Omega 2021, 6, 27702-27710 \\ Read Online
}

ACCESS | Lلll Metrics \& More | 回 Article Recommendations | S1 Supporting Information

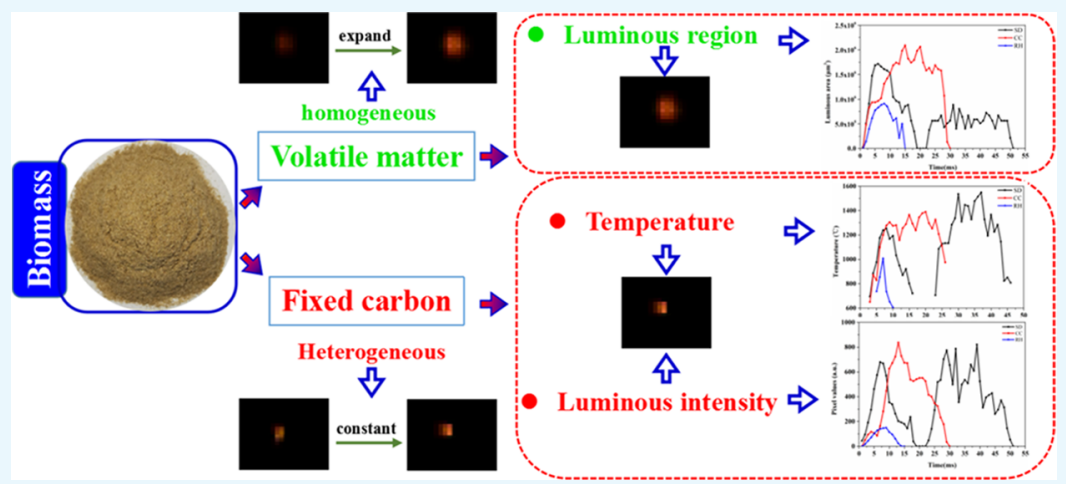

ABSTRACT: This work established a high-speed camera-assisted visualization system that investigated the effect of volatile matter and fixed carbon content in biomass particles on single-particle combustion phases and their luminous properties. Three types of biomass particles, namely, sawdust (a mixture of pine and willow), corncob, and rice husk, were examined on a Hencken flat-flame burner. The luminous region and intensity of single biomass particles were closely related to the flammability and calorific value of biomass fuel and derived by analyzing a sequence of images captured using a high-speed camera. The combustion temperature was determined through analysis of its radiant energy. The results showed that the ignition mechanisms of volatile matter and fixed carbon corresponded to homogeneous and heterogeneous reactions, respectively. The maximum luminous region values of $1.75 \times$ $10^{6}, 2.1 \times 10^{6}$, and $1.0 \times 10^{6} \mu \mathrm{m}^{2}$ for sawdust (SD), corncob (CC), and rice husk ( $\left.\mathrm{RH}\right)$ correlated to the volatile matter content of each biomass sample, which was $69.38,74.15$, and $64.56 \%$, respectively. Because of the high fixed carbon content, the peak temperature of the SD particles could reach $1549{ }^{\circ} \mathrm{C}$. The luminous region and intensity of the combusting particles were significantly affected by the volatile matter and fixed carbon, respectively.

\section{INTRODUCTION}

Globally, as a renewable energy resource, biomass is seen as a $\mathrm{CO}_{2}$ neutral fuel due to the carbon cycle and because bioenergy is renewable in nature. ${ }^{1,2}$ However, biomass energy use accounts for only $14 \%$ of the total energy consumption. ${ }^{3,4}$ Biomass combustion is a convenient way for $\mathrm{CO}_{2}$ reduction, ${ }^{5}$ due to its $\mathrm{CO}_{2}$-neutral characteristics, and the relative ease of utilizing as a fuel in the existing pulverized fossil fuel-fired thermal power plants. 6,7

Solid biofuels have lower ignition temperatures, lower energy content, and shorter burnout times ${ }^{8}$ compared to coal. ${ }^{9}$ The volatile matter (VM) and fixed carbon (FC) content can significantly affect biomass combustion characteristics, and the ignition temperature and ignition time varied with the volatile mater content. ${ }^{10}$ However, biomass fuels exhibit varied combustion behavior and luminous properties due to their physical and chemical differences, internal mesh structure, and low particle density. ${ }^{6,11}$ For example, during the first combustion stage, the rapid release of $70-90 \%$ of the volatile matter in the powdered biomass can easily create combustion atmospheres. ${ }^{12}$
Moreover, the lower inorganic composition, especially for the ash content, of biomass leads to lower particulate matter emissions during particle combustion. ${ }^{13}$ These studies indicate that solid biofuels have advantages such as low ignition temperature, internal mesh structure, and low inorganic content during the combustion process. However, compared with coal, they also have disadvantages such as low energy density, low calorific value, and short burning time periods. All of the advantages and disadvantages of solid biofuels in the combustion process mentioned above are related to the fuel properties. Therefore, the effects of fuel properties on the combustion behaviors of biofuels are significant.

Received: May 27, 2021

Accepted: September 27, 2021

Published: October 12, 2021 
Understanding the varied combustion behaviors are simplified by the experimental investigation of single biomass particles. Various instruments and experimental set-ups such as the thermogravimetric analysis (TGA) system, ${ }^{14,15}$ drop-tube furnaces (DTFs), ${ }^{6,16}$ and Hencken flat-flame burner $(\mathrm{HFFB})^{17,18}$ are used for investigating the combustion properties of single biomass particles.

Among the various experimental setups mentioned, HFFB has the advantages of higher heating rates $\left(\sim 10^{5} \mathrm{~K} / \mathrm{s}\right)$ and higher temperatures $(>1500 \mathrm{~K})$ compared to TGA. ${ }^{19,20}$ Also, the HFFB provides an experimental condition that is able to simulate the combustion environment in an industrial setting of pulverized fuel burners, in which fuel particles are exposed to reducing conditions during the initial devolatilization stage to oxidation. ${ }^{8,21}$ In addition, the HFFB provides uniform heating with micro-diffusion flames emanating from the burner, and the desired gas temperatures are obtained by changing the gas composition downstream of the micro-flames. ${ }^{19,22}$

Visualization methods are often employed for in-depth, quantifiable analysis of single-particle combustion. High-speed cameras are used with HFFB to obtain a sequence of images from the combustion of the single particles. ${ }^{23}$ However, these studies mainly investigated the combustion properties of coal particles, with the development of bioenergy, HFFB is increasingly applied to the combustion of single biomass particles. Zhang et al. ${ }^{24}$ reported that the fluctuation in the gas temperature significantly affects the instantaneous reaction of carbon in the biomass particles. Mock et al. ${ }^{25}$ observed that torrefied (carbonized) biomass has different ignition delay times and flame structures compared to nontorrefied biomass. Wang et al. ${ }^{26}$ observed that the ignition delay time of biomass particles was closely related to the moisture content of the particles. The above analyses did not elaborate on the effects of fixed carbon and volatile matter content on other combustion properties such as the luminous region and intensity. However, as two important indicators that can quantify the flammability and calorific value of biofuels, their importance cannot be ignored. The luminous region is representative of the volume or area of the emanating flame, and may not necessarily be correlated to the luminous intensity, which may be correlated to other factors such as the fixed carbon.

Therefore, this study investigates the combustion phases of single biomass particles, and establish the effect of volatile matter (VM) and fixed carbon (FC) content on lesser-known combustion properties such as the luminous region and intensity. HFFB that provides a uniform, fast-heating rate, coupled with a high-speed camera is used for flame visualization, from which the luminous region, intensity, and temperature are determined.

\section{EXPERIMENTAL METHODS}

2.1. Biomass Preparation. Three types of biomass samples were investigated in this study: sawdust (SD), corncob (CC), and rice husk $(\mathrm{RH})$. The samples were collected from Hubei province, China. The samples were first dried and pulverized, sieved to $180-250 \mu \mathrm{m}$ and dried at $105{ }^{\circ} \mathrm{C}$ for $12 \mathrm{~h}$ before each experiment. The properties of biomass samples are listed in Table 1, proximate and ultimate analyses were performed using a YSRZY-8 industrial analyzer (Yongxin, China) and an EA3000 elemental analyzer (Euro Vector, Italy), respectively. The fixed carbon and volatile matter mass fractions of SD, CC, and $\mathrm{RH}$ were $19.67,14.82,9.32 \%$, and $69.38,74.15,64.56 \%$, respectively.
Table 1. Proximate and Ultimate Analyses of the Biomass Fuels $^{a}$

\begin{tabular}{|c|c|c|c|}
\hline constituent & sawdust (SD) & corncob (CC) & rice husk $(\mathrm{RH})$ \\
\hline \multicolumn{4}{|c|}{ Proximate Analyses (wt \%, As Received) } \\
\hline fixed carbon (FC) & 19.67 & 14.82 & 9.32 \\
\hline volatile matter (VM) & 69.38 & 74.15 & 64.56 \\
\hline moisture content $(\mathrm{MC})$ & 8.91 & 9.51 & 11.58 \\
\hline ash content $(\mathrm{AC})$ & 2.04 & 1.52 & 14.54 \\
\hline $\mathrm{FC} / \mathrm{VM}(\%)$ & 28.35 & 19.99 & 14.44 \\
\hline \multicolumn{4}{|c|}{ Ultimate Analyses (wt \%, As Received) } \\
\hline $\mathrm{C}$ & 44.58 & 42.72 & 45.35 \\
\hline $\mathrm{H}$ & 5.50 & 5.66 & 5.30 \\
\hline $\mathrm{O}^{b}$ & 30.21 & 50.25 & 46.65 \\
\hline $\mathrm{N}$ & 1.14 & 0.50 & 0.79 \\
\hline $\mathrm{S}$ & 0.03 & 0.04 & 0.13 \\
\hline \multicolumn{4}{|c|}{ Heating Value $(\mathrm{MJ} / \mathrm{kg})$} \\
\hline & 18.83 & 16.01 & 14.25 \\
\hline
\end{tabular}

${ }^{a} \mathrm{FC}=$ fixed carbon, $\mathrm{M}=$ moisture, $\mathrm{VM}=$ volatile matter . ${ }^{b}$ Determined by difference.

SD has the highest fixed carbon content, and CC has the highest volatile matter content.

2.2. Experimental Setup. Figure 1 shows the experimental setup that consisted of a HFFB, mass flow controllers



Figure 1. Schematic structure of the HFFB utilized in this work.

(Sevenatar, China), a piezo bowl vibratory feeder (Sanki PEF90A, Japan), and a high-speed camera (Fastcam SA4, Japan). The HFFB is composed of a ceramic honeycomb (cross-section: $55 \times 55 \mathrm{~mm}^{2}$ ) that houses an array of 486 stainless-steel tubes (inside diameter: $0.8 \mathrm{~mm}$; outer diameter: $1.2 \mathrm{~mm}$ ). Mass flow controllers were used for controlling the fuel gas flow rates of air (15 slpm) and methane $(0.8 \mathrm{slpm})$ to provide a hightemperature environment. As the flow rate of each gas is independently controlled, and the high-frequency vibration of the vibratory feeder separates the particles from each other, the desired number density of particles can be obtained. Biomass particles were injected into the HFFB using a vibratory feeder, using $\mathrm{N}_{2}(0.5 \mathrm{slpm})$ as a carrier gas through a central stainlesssteel tube (internal diameter: $2.8 \mathrm{~mm}$ ). The high-speed camera with an AF Zoom-Nikkor 24-85 mm f/2.8-4D lens can acquire $1024(\mathrm{~h}) \times 1024(\mathrm{v})$ images, and has a maximum shutter speed of $3600 \mathrm{fps}$. The pixel values and shutter speed were varied to obtain high-definition images of the flame during single biomass particle combustion. 

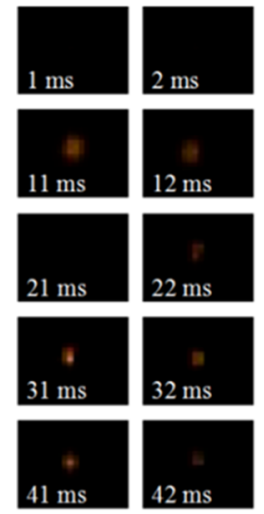

$42 \mathrm{~ms}$
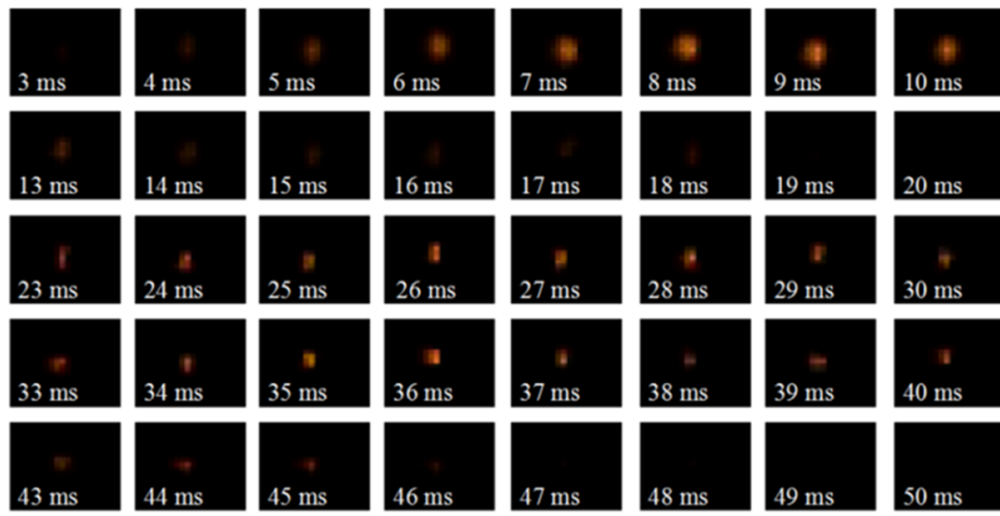

(a)

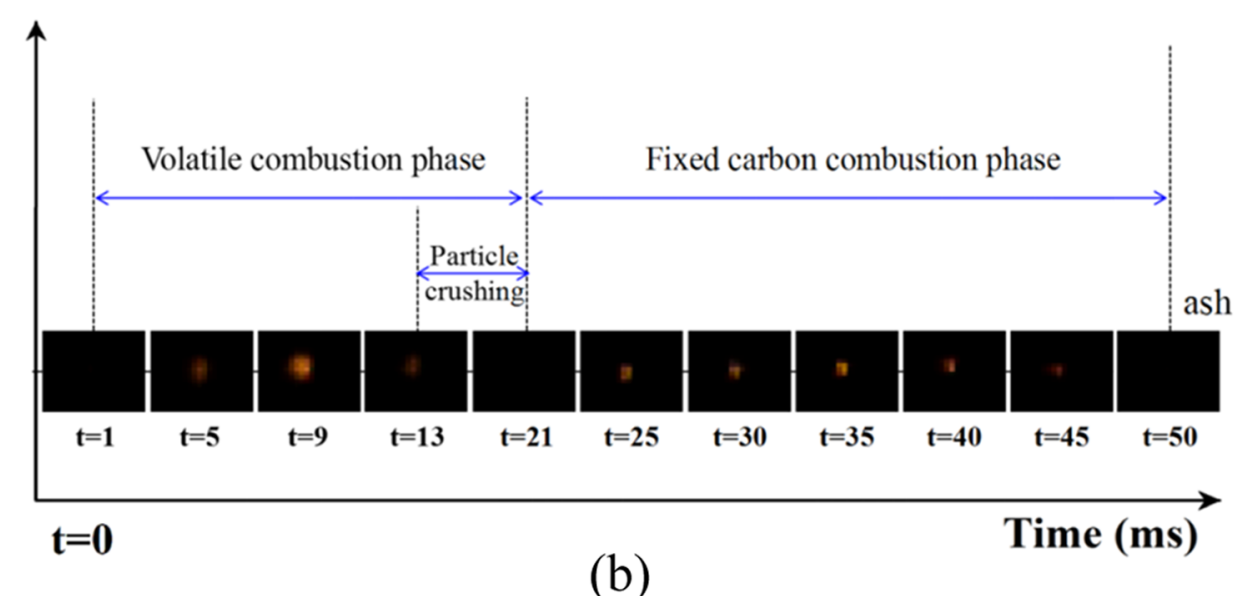

(b)
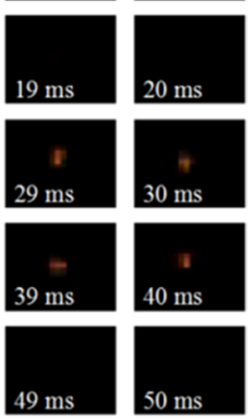

Figure 2. (a) Entire combustion process and (b) combustion phases diagram of SD.

2.3. Visualization Principle. All images were captured under a 12-bit resolution of the high-speed camera and the intensity of each pixel in the images is within 0 to 4096 . According to the colorimetry principle, the images are composed of three primary colors: red (R), green $(G)$, and blue (B). The image of a particle flame is a two-dimensional projection of a three-dimensional combustion field, from which a range of physical parameters of the single biomass particle combustion can be obtained using image processing techniques. In this study, to quantify and visualize the combustion or luminous properties of the single biomass particles, the parameters of the burning particle flame are classified into four main categories as follows.

(a) Burning time $(\tau)$ is defined as the duration from the start of the biomass particle combustion to complete flameout. A pixel intensity of greater than 20 is used to identify the onset of an emanating flame.

(b) Luminous region $\left(R_{1}\right)$ is defined as the area occupied by the particle flame and is obtained by the number of pixels occupied by the flame. The pixel values are converted to length measurements by eq 1

$$
S=n L^{2}
$$

where $L$ is the actual length of a pixel, $113.63 \mu \mathrm{m}$ (as shown in Figure S1), and $n$ is the number of pixels occupied by the flame.

(c) Luminous intensity $\left(I_{1}\right)$ is defined as the average brightness of the luminous region, determined by the $R$ value (intensity of red colors) in the flame image. A higher value of $I_{1}$ indicates a more intense flame.

(d) Particle temperature $\left(T_{\mathrm{p}}\right)$ represents the average temperature of the flame in the luminous region, which can be derived from the radiant energy analysis technology as follows.

The monochromatic radiation intensities of RGB bands in the color image are recorded using a high-speed camera. The blue color B-band is usually weak from a flame is often not used for analysis. The relationship between monochromatic radiation intensity $\left(I_{\lambda}\right)$ of the R and G-bands are obtained from the blackbody furnace and is derived by Wien's law ${ }^{27}$

$$
I_{\lambda}=\frac{\varepsilon_{\lambda} C_{1}}{\pi \lambda^{5}} \exp \left(-\frac{C_{2}}{\lambda T}\right)
$$

where $T$ is the blackbody furnace temperature, $\varepsilon_{\lambda}$ is the emissivity constant (0.99), and $\lambda$ is the wavelength of $\mathrm{R}$ or $\mathrm{G}$.

The high-speed camera has been calibrated with a blackbody furnace, and Figure S2 shows that the values of R and G-bands are linear with the monochromatic radiation intensities of $I_{R}$ and $I_{\mathrm{G}}$, and has a linear relationship as follows

$$
\begin{aligned}
& I_{\mathrm{R}}=f(\mathrm{R})=a_{0}+a_{1} \mathrm{R}+a_{2} \mathrm{R}^{2}+\cdots+a_{n} \mathrm{R}^{n} \\
& I_{\mathrm{G}}=f(\mathrm{G})=b_{0}+b_{1} \mathrm{G}+b_{2} \mathrm{G}^{2}+\cdots+b_{n} \mathrm{G}^{n}
\end{aligned}
$$

The coordinates of the combustion points in the image are $\left(i_{0}\right.$, $j_{0}$ ), the combustion temperature of the single particles was calculated by the two-color method. And the monochromatic 

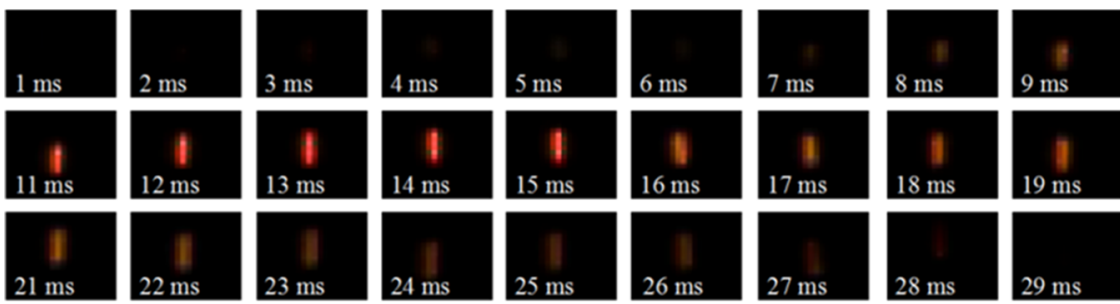

(a)

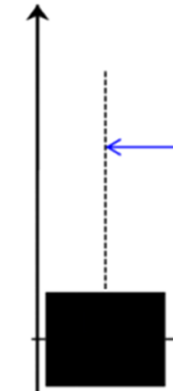

$\mathbf{t}=\mathbf{1}$

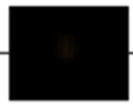

$\mathbf{t}=\mathbf{5}$

$\mathbf{t}=\mathbf{0}$
Volatile combustion phase

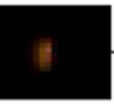

$\mathbf{t}=\mathbf{9}$
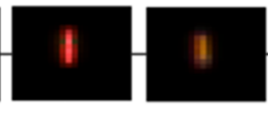

$\mathbf{t}=\mathbf{1 7}$

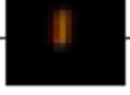

$\mathbf{t}=\mathbf{2 1}$

$\mathbf{t}=\mathbf{2 5}$

Time (ms)

(b)

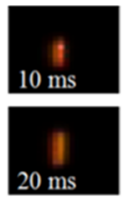

Figure 3. (a) Entire combustion process and (b) combustion phase diagram of CC.

radiation intensity $I_{\mathrm{R}}\left(i_{0}, j_{0}\right)$ and $I_{\mathrm{G}}\left(i_{0}, j_{0}\right)$ corresponding to the $\lambda_{\mathrm{R}}$ and $\lambda_{\mathrm{G}}$, and can be obtained from Wien's law of radiation as follows 28

$$
\frac{I_{\mathrm{R}}\left(i_{0}, j_{0}\right)}{I_{\mathrm{G}}\left(i_{0}, j_{0}\right)}=\frac{\varepsilon\left(\lambda_{\mathrm{R}}\right) \lambda_{\mathrm{G}}^{5}}{\varepsilon\left(\lambda_{\mathrm{G}}\right) \lambda_{\mathrm{R}}^{5}} \exp \left(-\frac{C_{2}}{T\left(i_{0}, j_{0}\right)}\left(\frac{1}{\lambda_{\mathrm{R}}}-\frac{1}{\lambda_{\mathrm{G}}}\right)\right)
$$

The flame temperature can be calculated from the corresponding monochromatic radiation intensity $I_{R}$ and $I_{\mathrm{G}}$ in the color image

$$
T\left(i_{0}, j_{0}\right)=-C_{2}\left(\frac{1}{\lambda_{\mathrm{R}}}-\frac{1}{\lambda_{\mathrm{G}}}\right) / \ln \left(\frac{I_{\mathrm{R}}\left(i_{0}, j_{0}\right) \lambda_{\mathrm{R}}{ }^{5}}{I_{\mathrm{G}}\left(i_{0}, j_{0}\right) \lambda_{\mathrm{G}}{ }^{5}}\right)
$$

\section{RESULTS AND DISCUSSION}

3.1. Gas Temperature of HFFB. Figure $S 3$ a shows the flat flame formed by the fuel gas, the upper flame level was flush with the central tube and the height of the flame was about $3 \mathrm{~mm}$, and the gas temperature along the central tube of the HFFB was measured using a B-type thermocouple and presented in Figure $\mathrm{S} 3 \mathrm{~b}$. Based on the radiation correction of the thermocouple temperature measurement, the relative error was $2-5 \%$, indicating that the corrected or modified temperature is similar to the experimental measurements. ${ }^{29}$

3.2. Visualization of the Combustion Images. This section discusses the ignition mechanisms and combustion phases of a single biomass particle. Figure 2 shows a series of photographic snapshots during the duration of the combustion of SD on the HFFB. As shown in Figure 2a, during the time $(t)$ of 1-7 $\mathrm{ms}$, the brightness of the biomass particles increased significantly. The maximum brightness or pixel intensity was observed at $7 \mathrm{~ms}$, which indicated that after ignition, the emitted volatile matter from the SD particles undergoes combustion. The central region of the particle was brighter and more luminous, indicating that the volatile matter in the particles is likely to be ignited first with the gaseous phase oxygen. The gasto-gas phase reactions indicate a homogeneous ignition mode, which is directly related to the volatile matter content. ${ }^{17}$ For $t=8$ ms onward, the brightness of the particles decreased to a minimum value at $t=18 \mathrm{~ms}$, indicating that the volatile matter in the SD particle is completely emitted, with a lack of brightness or luminous intensity (flameout) at $t=19-22 \mathrm{~ms}$. The brightness increased again at $t=23 \mathrm{~ms}$ in the form of a cap-shaped flame, with a more uniform distribution of luminosity across the particle, indicating that the particle is undergoing the later, slower gas-to-solid char (heterogeneous) reactions. ${ }^{30}$ The combustion stages of SD particles are presented in Figure $2 b$, showing that the volatile matter ignites the fixed carbon, a typical homogeneous-heterogeneous ignition process.

Figures $3 \mathrm{a}$ and $4 \mathrm{a}$ show that the combustion stages of $\mathrm{CC}$ and $\mathrm{RH}$ are similar, but differ from those of SD (Figure 2a). As shown in Figure 3a, the brightness and the luminous region of the particle increased from $t=1 \mathrm{~ms}$ to a maximum value at 13 ms. At $t=20 \mathrm{~ms}$ after ignition, the brightness of the particle decreased to a minimum at $30 \mathrm{~ms}$. Unlike the SD particles, the brightness of the images from CC particles did not increase again after the first flameout. This shows that the combustion phase of CC is mainly homogeneous oxidation of the volatiles. ${ }^{31}$ A similar combustion phase is observed for RH in Figure 4a. The figure shows that the maximum brightness was reached at $7 \mathrm{~ms}$. The minimum brightness was reached at $t=13 \mathrm{~ms}$, showing that the $\mathrm{RH}$ particles have flamed out. ${ }^{31}$ Figures $3 \mathrm{a}$ and $4 \mathrm{a}$ show that the CC and RH particles are likely to be combusted through a gaseous phase, volatile matter reactions because there are no staged changes in luminous brightness such as that of SD in Figure 2a,b. This is because of the lower fixed carbon-to-volatile matter (FC/VM) ratio of $\mathrm{CC}$ and $\mathrm{RH}$ compared to $\mathrm{SD}$, which is shown in Table 1 and Figure $2 \mathrm{~b}$. Figure $3 \mathrm{~b}$ shows that the duration for the combustion of the CC particle was $29 \mathrm{~ms}$. Figure $4 \mathrm{~b}$ shows that for $\mathrm{RH}$ particle, the combustion duration is only $13 \mathrm{~ms}$ due to a low VM and FC content (relative to SD and 

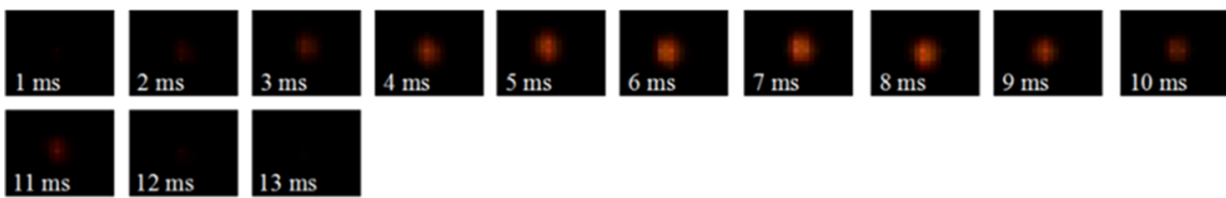

(a)

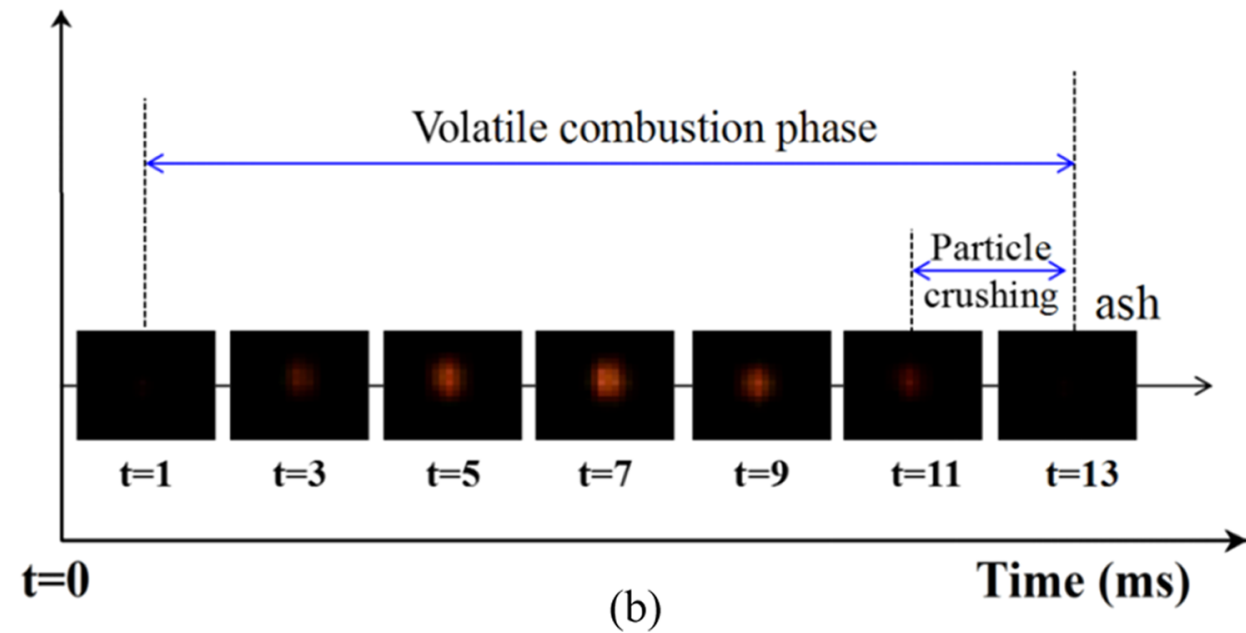

Figure 4. (a) Entire combustion process and (b) combustion phase diagram of RH.

CC). In addition, $\mathrm{RH}$ particles contain a significantly higher amount of ash content (14.44\%) compared to SD and CC (2.04 and $1.52 \%$ ), inhibiting the possibility of a longer combustion process.

As shown in Table 2, The above experiments were repeated 10 times, from which the mean and standard deviations of the

Table 2. Average Duration of Combustion for the Three Biomass Samples

\begin{tabular}{lccccc} 
& \multicolumn{2}{c}{ volatile combustion } & & \multicolumn{2}{c}{ fixed carbon burnout time } \\
\cline { 2 - 3 } & $\begin{array}{c}\text { mean value } \\
(\mathrm{ms})\end{array}$ & $\begin{array}{c}\text { standard } \\
\text { deviation }(\mathrm{ms})\end{array}$ & & $\begin{array}{c}\text { mean value } \\
(\mathrm{ms})\end{array}$ & $\begin{array}{c}\text { standard } \\
\text { deviation }(\mathrm{ms})\end{array}$ \\
sawdust & 18.75 & 3.28 & & 30.13 & 5.38 \\
corncob & 29.57 & 3.10 & & & \\
rice husk & 10.67 & 2.73 & & &
\end{tabular}

homogeneous and heterogeneous combustion times were obtained. Figure 5 shows the combustion duration or burnout times and the average times for the gaseous phase volatile matter reactions and the gas-to-solid phase fixed carbon reactions (for sawdust). The above results suggest that biofuels with a high fixed carbon content will undergo two combustion phases (the volatile matter and fixed carbon combustion phases). When heating, the volatile matter in the particles is released first to undergo gas-to-gas phase (homogeneous) reactions, indicating that the volatile matter has good flammability. ${ }^{32}$ On burning embers with the volatile matter, fixed carbon is ignited, this shows that fixed carbon requires a higher temperature to be ignited compared to volatile matter. ${ }^{8}$ The longer combustion duration of fixed carbon may be mainly attributed to the stronger $\mathrm{C}-\mathrm{C}$ bonding in fixed carbon. ${ }^{20}$

3.3. Effect of Biomass Properties on the Luminous Region $\left(R_{1}\right)$. Figure 6 shows that the luminous region $\left(R_{1}\right)$ (from eq 1 ) of the three biomass particles was changed during the combustion process. The $R_{1}$ of the biomass particle flame is directly affected by the volatile matter and fixed carbon content. As shown in Figure 6, in the volatile matter combustion phase, the $R_{1}$ after $t=1 \mathrm{~ms}$ increased significantly to maximum values of $1.75 \times 10^{6}, 2.1 \times 10^{6}$, and $1.0 \times 10^{6} \mu \mathrm{m}^{2}$ for SD, CC, and $\mathrm{RH}$, respectively. This is mainly due to the rapid release of the volatile matter and easily formed combustion atmospheres. Meanwhile, it also suggests that the volatile matter in biofuels has good flammability. ${ }^{32}$ The maximum $R_{1}$ levels of SD, CC, and $\mathrm{RH}$ correlate to the volatile matter contents of each biomass sample, which are $69.38,74.15$, and $64.56 \%$, respectively. Therefore, $R_{1}$ is greatly affected by the volatile matter content and is positively correlated. ${ }^{8}$ As the volatile matter content in $\mathrm{CC}$ is the highest, the corresponding $R_{1}$ is the highest as well. As mentioned earlier, due to a higher fixed carbon content, the SD particles went through a second, heterogeneous, fixed carbon oxidation stage. In this stage, the $R_{1}$ is smaller than that in the volatile matter combustion stage. These results indicate that compared with fixed carbon, the effect of the volatile matter content on $R_{1}$ of particles is more significant, biofuels containing more volatile matter have a larger value of $R_{l}$. Because of the positive association between volatile matter content and the $R_{1}$ level, $R_{1}$ can be used for the quantitative evaluation of the flammability of the biofuels.

3.4. Effect of Biomass Properties on the Luminous Intensity $\left(I_{1}\right)$. Figure 7 shows that for the luminous intensity $\left(I_{1}\right)$ of SD particles, due to a higher fixed carbon content, the second, heterogeneous combustion phase $(20-51 \mathrm{~ms})$ is higher in luminous intensity than the first, homogeneous combustion phase $(1-19 \mathrm{~ms})$. The $I_{1}$ of the fixed carbon combustion phase could reach a peak value of 800 pixels for a relatively longer duration, but for the volatile matter combustion phase, the maximum was 700 pixels that occurred within a short duration, indicating that fixed carbon can provide stronger radiation capacity and higher calorific value, the results are consistent with the conclusions obtained in Section 3.5. Compared with SD particles, $\mathrm{CC}$ and $\mathrm{RH}$ could only observe the volatile matter 


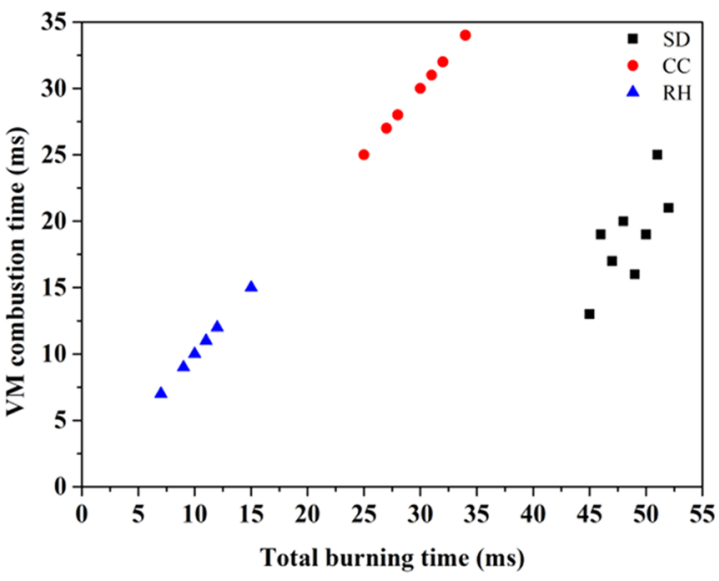

(a)

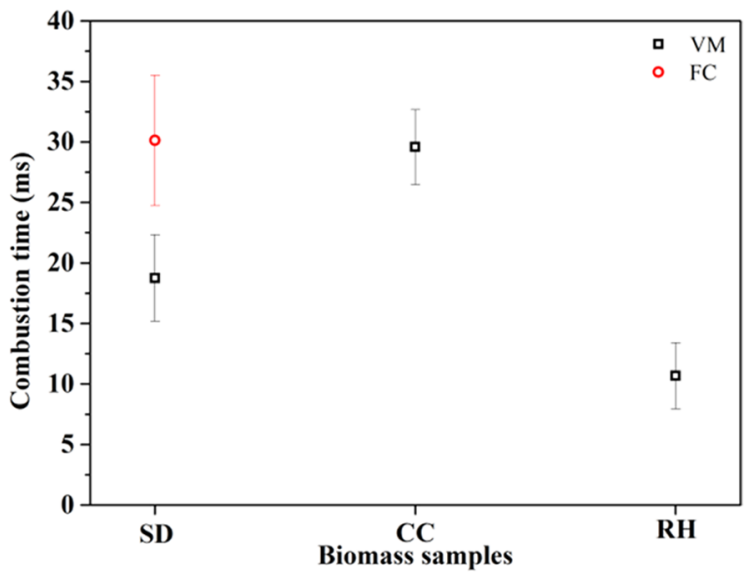

(b)

Figure 5. (a) Entire combustion time and (b) average burning time of the VM and FC.

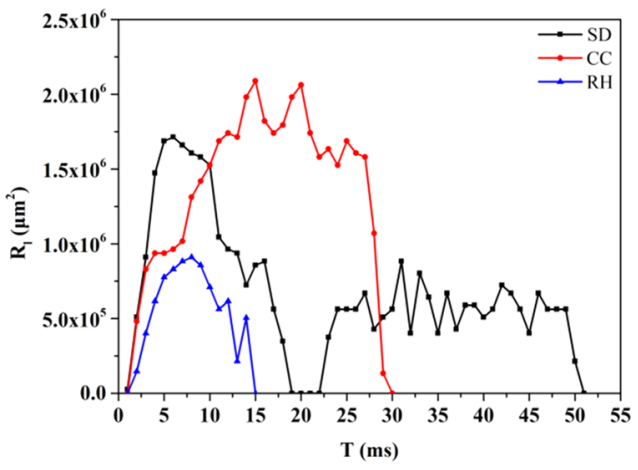

Figure 6. Luminous region $\left(R_{\mathrm{l}}\right)$ of the three biomass particles versus time.

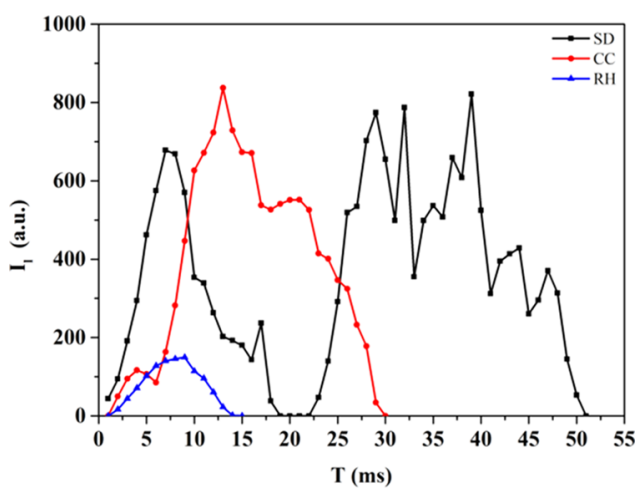

Figure 7. Luminous intensity $\left(I_{1}\right)$ of three biomass particles versus time.

combustion phase. This result is consistent with a previous study. ${ }^{20}$ A drop-tube furnace was employed by Riaza et al. ${ }^{20}$ to investigate the combustion behavior of four kinds of single particles, they found that sugarcane bagasse, pine sawdust, and torrefied pine sawdust only had one volatile matter combustion stage. Although both the CC and RH particles also contain fixed carbon, the combustion phase of fixed carbon was not observed, which was possibly assumed to be hidden by the main combustion stage. During the volatile matter combustion phase, the maximum $I_{1}$ of the three biomass samples was closely related to the volatile matter content. The order of the volatile matter content in the three biomass samples is CC $(74.15 \%)>$
SD $(69.38 \%)>\mathrm{RH}(64.56 \%)$. The CC particles have the maximum $I_{1}$ value, indicating that during the volatile matter combustion phase, the volatile matter content directly affects the $I_{1}$ of the burning particles. In the fixed carbon combustion stage, the $I_{1}$ of the burning particle (specifically, $I_{1}$ of sawdust) is greater than that of the volatile matter combustion, and fixed carbon content has a greater impact on the $I_{1}$. The reason for this is that the $\mathrm{C}-\mathrm{C}$ bond in the fixed carbon can provide higher energy than that in the volatile matter. ${ }^{32}$

3.5. Effect of Biomass Properties on the Particle Temperature $\left(T_{\mathrm{p}}\right)$. Figure $8 \mathrm{a}$ shows the temperature cloud map of the single biomass particles during combustion. The figure shows the movement trajectories and morphological changes of the particles. The combustion of the SD, CC, and $\mathrm{RH}$ particles occurs in the region of $0-80 \mathrm{~mm}$ above the surface of the burner. The specific temperature change is shown in Figure 8 b. As shown in Figure $8 \mathrm{~b}$, due to different volatile matter and fixed carbon content, the temperatures of ignited single biomass particles were significantly different. For SD particles, throughout the burning phase, there were two peak values of the combustion temperature, 1253 and $1549{ }^{\circ} \mathrm{C}$, which appeared in the volatile matter and fixed carbon combustion phase, respectively. The overall $T_{\mathrm{p}}$ of the fixed carbon combustion phase was higher than that of the volatile matter combustion phase, indicating that the effect of the fixed carbon content on $T_{\mathrm{p}}$ is stronger than the volatile matter content, and the fixed carbon can provide a higher calorific value than volatile matter. ${ }^{8,16}$ For CC and RH particles, their combustion phases were similar and consisted of only the volatile matter combustion phase. Due to the high volatile matter content of $\mathrm{CC}$, at $3 \mathrm{~ms}$ after ignition, the volatile matter was released instantaneously as the particle was heated. The particle temperature increased rapidly, and the maximum $T_{\mathrm{p}}$ was 1400 ${ }^{\circ} \mathrm{C}$ at $10 \mathrm{~ms}$ after ignition. As for $\mathrm{RH}$ particles, due to both low volatile matter and fixed carbon content, the $T_{\mathrm{p}}$ increased at a slower rate compared to $\mathrm{CC}$, and the maximum $T_{\mathrm{p}}$ of $\mathrm{RH}$ was only $1008{ }^{\circ} \mathrm{C}$. These results prove that the higher calorific value contained in fixed carbon is higher than that of the volatile matter, the combustion temperature mainly depends on the rate of heat release and is different from the gas temperature. In addition, the combustion temperature obtained in the experiment is slightly lower than that obtained in the simulation process, mainly because the simulation process is carried out 


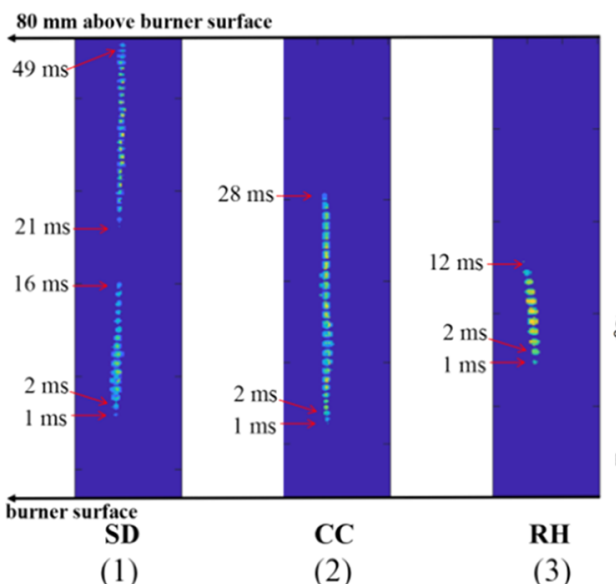

(a)

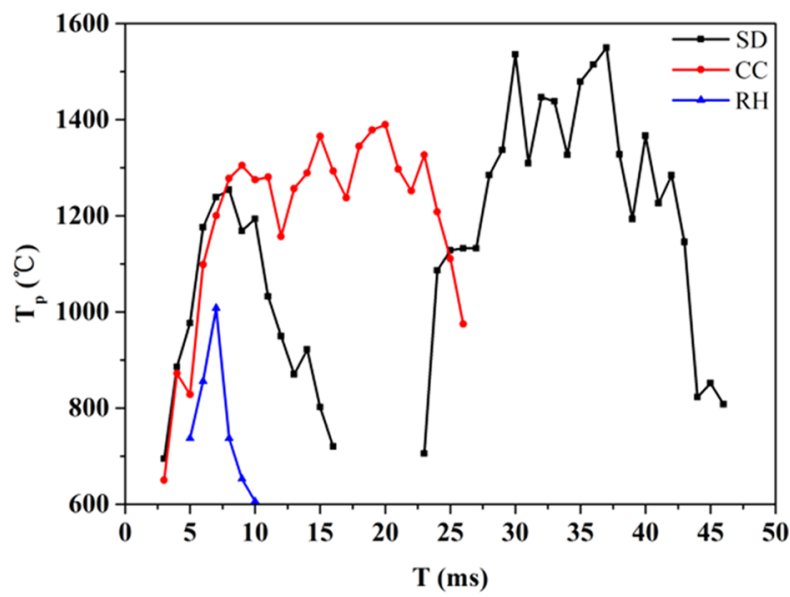

(b)

Figure 8. (a) Temperature cloud map of $\mathrm{SD}, \mathrm{CC}$, and $\mathrm{RH}$ and (b) the particle temperature $\left(T_{\mathrm{p}}\right)$ of the three biomass particles versus time.

under ideal conditions, which is different from the actual combustion environment, but the overall trend of the combustion process is consistent. ${ }^{33}$ the results are consistent with the conclusions obtained in Section 3.4.

3.6. Average Values of $R_{l}, I_{l}$, and $T_{\mathrm{p}}$. The experiments employed many biomass particles and were repeated 10 times, then the average values of the $R_{\mathrm{b}}, I_{1}$, and $T_{\mathrm{p}}$ of the three biomass samples were obtained and are presented in Figure 9. Due to a

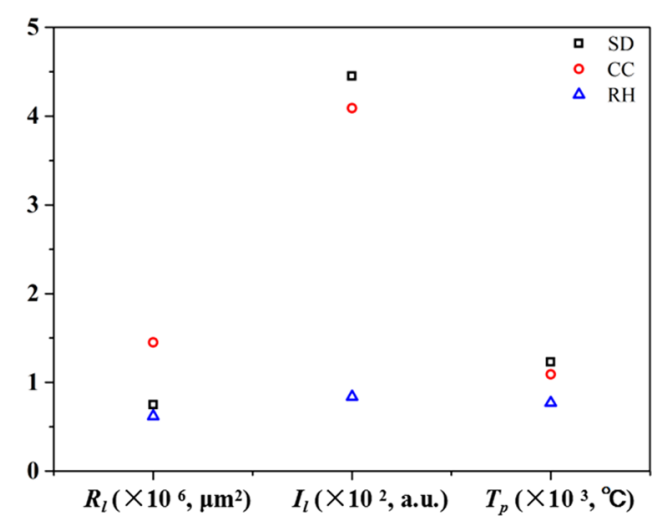

Figure 9. Average values of the luminous region $\left(R_{\mathrm{l}}\right)$, luminous intensity $\left(I_{1}\right)$, and particle temperature $\left(T_{\mathrm{p}}\right)$ of the three biomass samples.

higher fixed carbon content, the averaged luminous intensity $\left(I_{1}\right)$ and temperature $\left(T_{\mathrm{p}}\right)$ were the highest for $\mathrm{SD}$, which were 4.52 $\times 10^{2}$ and $1451{ }^{\circ} \mathrm{C}$. This is because the fixed carbon content contains energetic carbon-to-carbon bonds, ${ }^{32}$ which releases the most energy and heat, thus increasing the luminous intensity. $\mathrm{CC}$ has the highest volatile matter content and releases a higher amount of combustible volatiles. The higher amount of combustible volatiles is reflected in the larger luminous region $\left(R_{1}\right)$ of $1.51 \mu \mathrm{m}^{2}$ for CC. The results indicate that the volatile matter affects the $R_{1}$ values, and the fixed carbon affects the values of $I_{1}$ and $T_{\mathrm{p}}$.

3.7. Effects of Fuel Properties on the Combustion Phases of Biomass. According to the analysis above, the volatile matter and fixed carbon content in the biomass particles strongly influence their combustion behaviors. Upon heating, the volatile matter is released rapidly and the $R_{1}$ after $t=1 \mathrm{~ms}$ increased significantly to the maximum values of $1.75 \times 10^{6}, 2.1$ $\times 10^{6}$, and $1.0 \times 10^{6} \mu \mathrm{m}^{2}$ for $\mathrm{SD}, \mathrm{CC}$, and $\mathrm{RH}$, respectively, and particles exhibited homogeneous ignition behavior. Fixed carbon needs to be ignited at a higher temperature due to the stronger $\mathrm{C}-\mathrm{C}$ bonding, therefore, the fixed carbon combustion phase is carried out after the volatile matter combustion stage, corresponding to the slower gas-to-solid char (heterogeneous) reactions. $^{34}$

First, CC has the highest VM content, therefore, compared to $\mathrm{SD}$ and $\mathrm{RH}, \mathrm{CC}$ has the longest volatile combustion phase (Figure 5). As shown in Figure 6, the maximum luminous region values of $1.75 \times 10^{6}, 2.1 \times 10^{6}$, and $1.0 \times 10^{6} \mu \mathrm{m}^{2}$ for SD, CC, and $\mathrm{RH}$ correlate to the volatile matter content of each biomass sample, which is $69.38,74.15$, and $64.56 \%$, respectively. Because of the positive correlation between the luminous region and the fuel flammability, the volatile matter content has a great impact on the fuel flammability. ${ }^{17}$

Second, the fixed carbon content made the main contribution to the maximum combustion temperature value of the biomass particle (Figure 8), mainly due to the strong $\mathrm{C}-\mathrm{C}$ bonding in the fixed carbon. ${ }^{32}$ The results show that the volatile matter and fixed carbon content play a significant role in the combustion phases and their luminous properties. The fuel flammability and combustion temperature of biomass particles can be quantitatively analyzed by volatile matter and fixed carbon content, respectively.

\section{CONCLUSIONS}

This work investigated the effect of volatile matter and fixed carbon content in biomass particles on the combustion phases and their luminous properties. Single particles were burned on a Hencken flat-flame burner coupled with a high-speed camera. The combustion phases and their luminous properties were characterized and the following conclusions can be drawn:

(1) Both volatile matter and fixed carbon content strongly influenced the combustion behaviors of the biomass particles. Biomass particles with high fixed carbon content underwent two combustion phases: the volatile matter and fixed carbon combustion phases, which correspond to homogeneous and heterogeneous reactions, respectively.

(2) During the volatile matter combustion phase, when heating, the volatile matter in biomass particles was released first, the $R_{1}$ after $t=1 \mathrm{~ms}$ increased significantly to 
the maximum values of $1.75 \times 10^{6}, 2.1 \times 10^{6}$, and $1.0 \times$ $10^{6} \mu \mathrm{m}^{2}$ for $\mathrm{SD}, \mathrm{CC}$, and $\mathrm{RH}$, respectively, and particles exhibited homogeneous ignition behavior.

(3) Throughout the burning phase, there were two peak values of the combustion temperature, 1253 and $1549{ }^{\circ} \mathrm{C}$, which appeared in the volatile matter and fixed carbon combustion phase, respectively. The fixed carbon was ignited at the end of the volatile matter combustion stage. In the bright, relatively stable fixed carbon combustion phase, The maximum combustion temperature of the burning particles depended mainly on the fixed carbon.

\section{ASSOCIATED CONTENT}

\section{SI Supporting Information}

The Supporting Information is available free of charge at https://pubs.acs.org/doi/10.1021/acsomega.1c02783.

Correspondence diagram of actual scale and pixel value, the monochromatic radiation intensity of $I_{\mathrm{R}}$ versus $\mathrm{R}$ and $I_{\mathrm{G}}$ versus $\mathrm{G}$, the flat-flame diagram and gas temperature of the combustion products along the centerline of the HFFB (PDF)

\section{AUTHOR INFORMATION}

\section{Corresponding Authors}

Chun Lou - State Key Laboratory of Coal Combustion, School of Energy and Power Engineering, Huazhong University of Science and Technology, Wuhan 430074, P. R. China; (1) orcid.org/0000-0003-3302-7210; Email: lou_chun@ sina.com

Bo Xiao - School of Environmental Science \& Engineering, Huazhong University of Science and Technology, Wuhan 430074, P. R. China; Email: xiaobo1958@hust.edu.cn

\section{Authors}

Yongsheng Jia - School of Environmental Science \& Engineering, Huazhong University of Science and Technology, Wuhan 430074, P. R. China

Zhicong Li - State Key Laboratory of Coal Combustion, School of Energy and Power Engineering, Huazhong University of Science and Technology, Wuhan 430074, P. R. China

Yingjie Wang - School of Environmental Science \& Engineering, Huazhong University of Science and Technology, Wuhan 430074, P. R. China

Xun Wang - School of Environmental Science \& Engineering, Huazhong University of Science and Technology, Wuhan 430074, P. R. China

Mooktzeng Lim - Biomass and Plasma Technologies, Renewable Energy and Green Technology, TNB Research Sdn. Bhd., Kajang 43000 Selangor, Malaysia

Complete contact information is available at:

https://pubs.acs.org/10.1021/acsomega.1c02783

\section{Notes}

The authors declare no competing financial interest.

\section{ACKNOWLEDGMENTS}

This work was supported by the National Natural Science Foundation of China (Nos. 22075093 and 21975089).

\section{ABBREVIATIONS}

$\mathrm{R}, \mathrm{G}$, and $\mathrm{B}$ the three primary colors of the images $\tau$

$R_{1}$

$I_{1} \quad$ the average brightness of the luminous region

$T_{\mathrm{p}} \quad$ the average temperature of the flame in the luminous region

\section{REFERENCES}

(1) Ahmed, M.; Batalha, N.; Mahmudul, H. M.; Perkins, G.; Konarova, M. A review on advanced catalytic co-pyrolysis of biomass and hydrogen-rich feedstock: Insights into synergistic effect, catalyst development and reaction mechanism. Bioresour. Technol. 2020, 310, No. 123457.

(2) Banu, J. R.; Buitrón, G.; Martin, K.; Kumar, G. Recent advances in biopolymers production from biomass and waste (RABP-2020). Bioresour. Technol. 2021, 328, No. 124879.

(3) Anca-Couce, A.; Sommersacher, P.; Hochenauer, C.; Scharler, R. Multi-stage model for the release of potassium in single particle biomass combustion. Fuel 2020, 280, No. 118569.

(4) Sui, B. L.; Wu, H. Importance of flue gas cooling conditions in particulate matter formation during biomass combustion under conditions pertinent to pulverized fuel applications. Proc. Combust. Inst. 2020, 38, 5201-5208.

(5) Motyl, P.; Król, D.; Poskrobko, S.; Juszczak, M. Numerical Modelling and Experimental Verification of the Low-Emission Biomass Combustion Process in a Domestic Boiler with Flue Gas Flow around the Combustion Chamber. Energies 2020, 13, No. 5837.

(6) Wang, S.; Zou, C.; Yang, H.; Lou, C.; Cheng, S.; Chao, P.; Cong, W.; Zou, H. Effects of cellulose, hemicellulose, and lignin on the combustion behaviours of biomass under various oxygen concentrations. Bioresour. Technol. 2020, 320, 47-55.

(7) Wu, H.; Yu, Y.; Gao, X.; Xu, M.; Gong, X. Virtual Special Issue of 7th Sino-Australian Symposium on Advanced Coal and Biomass Utilisation Technologies. Energy Fuels 2020, 34, 3981-3983.

(8) Sheng, Q.; Wang, Z.; Costa, M.; Yong, H.; Cen, K. Ignition and combustion of single pulverized biomass and coal particles in $\mathrm{N}_{2} / \mathrm{O}_{2}$ and $\mathrm{CO}_{2} / \mathrm{O}_{2}$ environments. Fuel 2020, 283, No. 118956.

(9) Chen, X.; Liu, L.; Zhang, L.; Zhao, Y.; Ruan, R. A review on properties of co-pyrolysis char from coal blended with biomass. Energy Fuels 2020, 34, 3996-4005.

(10) Rybak, W.; Moron, W.; Ferens, W. Dust ignition characteristics of different coal ranks, biomass and solid waste. Fuel 2019, 237, 606618.

(11) Lu, H.; Ip, E.; Scott, J.; Foster, P.; Vickers, M.; Baxter, L. L. Effects of particle shape and size on devolatilization of biomass particle. Fuel 2010, 89, 1156-1168.

(12) Liu, A.; Chen, J.; Huang, X.; Lin, J.; Zhang, X. Explosion parameters and combustion kinetics of biomass dust. Bioresour. Technol. 2019, 294, No. 122168.

(13) Yin, C. Development in biomass preparation for suspension firing towards higher biomass shares and better boiler performance and fuel rangeability. Energy 2020, 196, No. 117129.

(14) Kopczyński, M.; Plis, A.; Zuwaa, J. Thermogravimetric and Kinetic Analysis of Raw and Torrefied Biomass Combustion. Chem. Process Eng. 2015, 36, 209-223.

(15) Toptas, A.; Yildirim, Y.; Duman, G.; Yanik, J. Combustion behavior of different kinds of torrefied biomass and their blends with lignite. Bioresour. Technol. 2015, 177, 328-336.

(16) Shan, L.; Kong, M.; Bennet, T. D.; Sarroza, A. C.; Eastwick, C.; Sun, D.; Lu, G.; Yan, Y.; Liu, H. Studies on combustion behaviours of single biomass particles using a visualization method. Biomass Bioenergy 2018, 109, 54-60.

(17) Lee, H.; Choi, S. Volatile flame visualization of single pulverized fuel particles. Powder Technol. 2018, 333, 353-363.

(18) Lou, C.; Pu, Y.; Zhao, Y.; Bai, Y.; Yao, B.; Yu, D. An in-situ method for time-resolved sodium release behaviour during coal 
combustion and its application in industrial coal-fired boilers. Proc. Combust. Inst. 2021, 38, 4199-4206.

(19) Adeosun, A.; Huang, Q.; Li, T.; Gopan, A.; Wang, X.; Li, S.; Axelbaum, R. L. Characterization of a new Hencken burner with a transition from a reducing-to-oxidizing environment for fundamental coal studies. Rev. Sci. Instrum. 2018, 89, No. 025109.

(20) Riaza, J.; Khatami, R.; Levendis, Y. A.; Alvarez, L.; Gil, M. V.; Pevida, C.; Rubiera, F.; Pis, J. J. Combustion of single biomass particles in air and in oxy-fuel conditions. Biomass Bioenergy 2014, 64, 162-174.

(21) Lou, C.; Zhou, H. C.; Yu, P. F.; Wei, Z. Measurements of the flame emissivity and radiative properties of particulate medium in pulverized-coal-fired boiler furnaces by image processing of visible radiation. Proc. Combust. Inst. 2007, 31, 2771-2778.

(22) Mason, P. E.; Darvell, L. I.; Jones, J. M.; Pourkashanian, M.; Williams, A. Single particle flame-combustion studies on solid biomass fuels. Fuel 2015, 151, 21-30.

(23) Magalhães, D.; Kazanc, F.; Ferreira, A.; Rabacal, M.; Costa, M. Ignition behavior of Turkish biomass and lignite fuels at low and high heating rates. Fuel 2017, 207, 154-164.

(24) Zhang, J.; Pang, J. Instantaneous char reaction of biomass particles in a hot gas flow with fluctuating temperature. Int. J. Green Energy 2016, 7, 1035-1041.

(25) Mock, C.; Park, H.; Ryu, C.; Manovic, V.; Choi, S.-C. Particle temperature and flue gas emission of a burning single pellet in air and oxy-fuel combustion. Combust. Flame 2020, 213, 156-171.

(26) Wang, X.; Adeosun, A.; Hu, Z.; Xiao, Z.; Khatri, D.; Li, T.; Tan, H.; Axelbaum, R. L. Effect of feedstock water leaching on ignition and PM 1.0 emission during biomass combustion in a flat-flame burner reactor. Proc. Combust. Inst. 2019, 37, 2705-2713.

(27) Lou, C.; Zhou, H. C. Deduction of the two-dimensional distribution of temperature in a cross section of a boiler furnace from images of flame radiation. Combust. Flame 2005, 143, 97-105.

(28) Lou, C.; Chen, C.; Sun, Y. P.; Zhou, H. C. Review of soot measurement in hydrocarbon-air flames. Sci. China Technol. Sci. 2010, $53,2129-2141$.

(29) Xu, Z.; Zhao, H.; Chen, X.; Lou, C. Multi-parameter measurements of laminar sooting flames using thermophoretic sampling technique. Combust. Flame 2017, 180, 158-166.

(30) Lee, H.; Choi, S. An observation of combustion behavior of a single coal particle entrained into hot gas flow. Combust. Flame 2015, $162,2610-2620$.

(31) Mohanna, H.; Commandre, J. M.; Piriou, B.; Vaitilingom, G.; Taupin, B.; Honore, D. Shadowgraphy investigation of the combustion of raw and pre-treated single biomass particles: Influence of particle size and volatile content. Fuel 2019, 258, No. 116113.

(32) Park, H.; Mock, C.; Ryu, C.; Choi, S. Combustion characteristics of single biomass pellets in a hot gas flow. J. Power Syst. Eng. 2019, 23, 91-104.

(33) Maffei, T.; Khatami, R.; Pierucci, S.; Faravelli, T.; Ranzi, E.; Levendis, Y. A. Experimental and modeling study of single coal particle combustion in $\mathrm{O}_{2} / \mathrm{N}_{2}$ and Oxy-fuel $\left(\mathrm{O}_{2} / \mathrm{CO}_{2}\right)$ atmospheres. Combust. Flame 2013, 160, 2559-2572.

(34) Wang, S.; Zou, C.; Lou, C.; Yang, H.; Cheng, S. Effects of hemicellulose, cellulose and lignin on the ignition behaviors of biomass in a drop tube furnace. Bioresour. Technol. 2020, 310, No. 123456. 